\title{
Desenvolvimento da versão para o português das Escalas de Criatividade ao Longo da Vida (ECLV)
}

\author{
Flávio Shansis*,** \\ Marcelo Pio de Almeida Fleck*** \\ Ruth Richards**** \\ Dennis Kinney ${ }^{* * * *}$ \\ Ivan Izquierdo* \\ Betina Mattevi** \\ Gabriela Maldonado***** \\ Marcelo Berlim***
}

\section{INTRODUÇÃO}

Em geral, quando o termo Criatividade vem à mente, este é associado a trabalhos artísticos ou a pesquisas científicas que rompem com paradigmas. Entretanto, a importância da criatividade não está confinada apenas a momentos de excelência, sejam nas Artes ou nas Ciências. Ao longo deste artigo, o conceito de criatividade utilizado será o de Barron e Harrington ${ }^{1}$ que contemplam dois critérios: o critério de ori-

\footnotetext{
Trabalho realizado nos Departamentos de Bioquímica e de Psiquiatria e Medicina Legal da Universidade Federal do Rio Grande do Sul.

0 presente artigo trata-se de parte da Tese de Doutoramento do primeiro autor junto ao Departamento de Bioquímica da Universidade Federal do Rio Grande do Sul.

* Departamento de Bioquímica da Universidade Federal do Rio Grande do Sul.

** Serviço de Psiquiatria do Hospital de Clínicas de Porto Alegre.

*** Departamento de Psiquiatria e Medicina Legal da Universidade Federal do Rio Grande do Sul .

**** Saybrook Graduate School e Department of Psychiatry, University of California, San Francisco.

***** Genetics laboratory, McLean Hospital / Harvard Medical School.

****** Serviço de Dermatologia Sanitária da Secretaria de Saúde do Estado do Rio Grande do Sul.
}

ginalidade e o de fazer sentido aos outros (mais do que simplesmente ser algo completamente idiossincrásico). Por esta definição, a maioria das atividades vocacionais e não-vocacionais pode ser realizada em graus variados de criatividade.

Além de ser algo que ocorre também no dia-a-dia de pessoas não-eminentes, a criatividade é igualmente fundamental em outras áreas que não apenas nas artes ou nas ciências, como em inovações tecnológicas, empresariais ou gerenciais, por exemplo. Assim como são necessárias inovações nas áreas científica e tecnológica, urgem também inovações nas áreas política, ética, cultural e ambiental para solucionar os enormes problemas globais existentes. Portanto, a habilidade das sociedades em identificarem o potencial criativo nos seus cidadãos é algo fundamental em nossos dias. Desta forma, para que pesquisas sejam realizadas na área da criatividade, tornam-se necessários métodos apropriados para a sua medição. Entretanto, medir a criatividade não é tarefa simples, e vários métodos e abordagens têm sido desenvolvidos para tentar acessar habilidades criativas na população. 
Hocevar e Bachelor ${ }^{2}$ identificaram oito tipos principais de trabalhos já realizados com o intuito de medir as capacidades criativas. Cabe ressaltar que esta identificação feita pelos autores contempla trabalhos que avaliam tanto produtos criativos quanto pessoas criativas, assim como o processo criativo. De forma geral, os principais tipos de trabalho no tema da criatividade podem ser agrupados em: a) trabaIhos com testes de pensamento divergente (por exemplo, Testes de Torrance para Pensamento Criativo $\left.{ }^{3,4}\right)$; b) inventários de atitudes e interesses; c) inventários de personalidade; d) inventários biográficos (as abordagens biográficas têm tentado usar os comportamentos e realizações ocorridas no passado para predizer criatividade futura. Essas abordagens biográficas vêm sendo usadas tanto em estudos de criativos eminentes quanto de não-eminentes ${ }^{5}$ ); e) avaliações por professores, colegas e supervisores (um exemplo dessa abordagem é a utilização, como juízes, de supervisores de trabaIhadores, colegas de estudantes ou professores, os quais são solicitados a avaliar quão criativos são determinados indivíduos nos seus desempenhos no trabalho ou na escola); f) julgamento dos produtos criativos (o produto criativo deve ser visto como algo novo que combina elementos de forma original, mostra adaptação e resulta em um produto único. Dentro desta abordagem, os cientistas e os artistas têm sido as amostras populacionais mais estudadas ${ }^{1}$ ); g) trabalhos com eminências (outro tipo de pesquisa é aquela que estuda indivíduos eminentes que sejam reconhecidos em seus campos de atuação como extraordinariamente criativos através, por exemplo, de prêmios artísticos ou científicos ${ }^{6,7,8,9}$ e h) auto-relato de realizações e atividades criativas (enquanto uma vasta literatura tem se centrado em realizações criativas de pessoas eminentes, há menos pesquisas baseadas na criatividade diária de pessoas não-eminentes).

Esta última abordagem - a da criatividade diária em pessoas não-eminentes - é bastante promissora, mas apresenta também dificuldades potenciais. Em geral, os pesquisadores não utilizam escalas para medir este tipo de criatividade ou, quando avaliam esta criatividade diária, não apresentam evidências de validade e confiabilidade das medidas utilizadas. Há, portanto, uma necessidade nesta área de pesquisa com escalas confiáveis e válidas para medir a criatividade diária. Essas escalas devem ser capazes de medir diferentes dimensões tanto da criatividade vocacional quanto da não vocacional em amostras heterogêneas de indivíduos não eminentes retirados da população geral. Foi com este intuito que as Escalas de Criatividade ao Longo da Vida (ECLV) de Richards, Kinney e Benet ${ }^{10}$ foram desenvolvidas (Anexo 1). Estas escalas foram concebidas com o objetivo de acessar tanto a qualidade quanto a quantidade de realizações criativas na vida adulta de um indivíduo. O foco destas escalas está nas atividades da vida real de uma determinada pessoa, tanto no trabalho quanto no lazer. As ECLV se focam no produto criativo (ou seja, nos produtos, comportamentos ou principais idéias que têm sido comunicadas aos outros) e levam, portanto, em conta tanto as atividades vocacionais quanto as não vocacionais. Desta forma, estas escalas vêm preencher um espaço importante na área de pesquisa em Criatividade e podem representar um avanço científico em nosso meio ao serem disponibilizadas em Língua Portuguesa para uso em pesquisas. O presente artigo tem por objetivo apresentar estas escalas descrevendo o instrumento propriamente dito, assim como o desenvolvimento de sua versão para o Português.

\section{DESCRIÇÃO DO INSTRUMENTO}

As ECLV usam dois critérios de criatividade amplamente aceitos: a) originalidade (isto é, para ser criativo um produto deve conter elementos novos ou não usuais) e b) ter sentido aos outros (isto é, um produto criativo que pode ser comunicado aos outros - mais do que ser dominado por elementos idiossincrásicos, bizarros ou randômicos).

Nestas escalas, a definição de criatividade usada é deliberadamente ampla e geral, qual seja, a criatividade é conceitualizada como algo que pode ocorrer virtualmente em qualquer tipo de empreendimento humano e em níveis variados de realizações. A criatividade é vista como uma qualidade ou uma capacidade que varia amplamente na população geral e pode se manifestar em uma grande variedade de produtos que envolvem virtualmente qualquer campo de atividade $^{10}$. Essa perspectiva guarda similitudes com a visão de criatividade expressa por psicólogos humanistas como Maslow ${ }^{11}$ e Rogers $^{12}$ e com o conceito de plasticidade fenotípica subjacente à inventividade e adaptabilidade que tem sido descrito por biologistas evolucionários (como por exemplo Dobzhansky ${ }^{13}$ ).

As ECLV apresentam no seu texto vários exemplos para ilustrar a identificação de elementos criativos e como estes elementos podem ser encontrados em uma variedade de contextos comuns. As variáveis centrais da cri- 
atividade envolvem estimativas tanto (a) do pico de criatividade ou (b) da extensão do envolvimento criativo, quanto (c) de uma estimativa da criatividade total. Esta abordagem permite identificar a máxima realização do potencial criativo de uma pessoa ("pico de criatividade"), assim como permite identificar a extensão do envolvimento criativo de uma pessoa (isto é, quão pervasiva é a atividade criativa na vida adulta de alguém). Os parâmetros utilizados por estas escalas são, portanto, os seguintes (Figura 1): 1.b) Pico de Criatividade Não Vocacional. É o nível máximo de inovação manifestado em uma importante realização durante o período de lazer de uma pessoa.

1.c) Pico de Criatividade - Vocacional e Não Vocacional. É o nível máximo de inovação demonstrado durante a vida adulta da pessoa em qualquer empreendimento, seja vocacional ou não vocacional. Este item permite se considerar a predisposição geral de alguém para a originalidade e pode dar o melhor parâmetro

\section{FIGURA 1}

\section{Pico de Criatividade Extensão do envolvimento Criatividade Total}

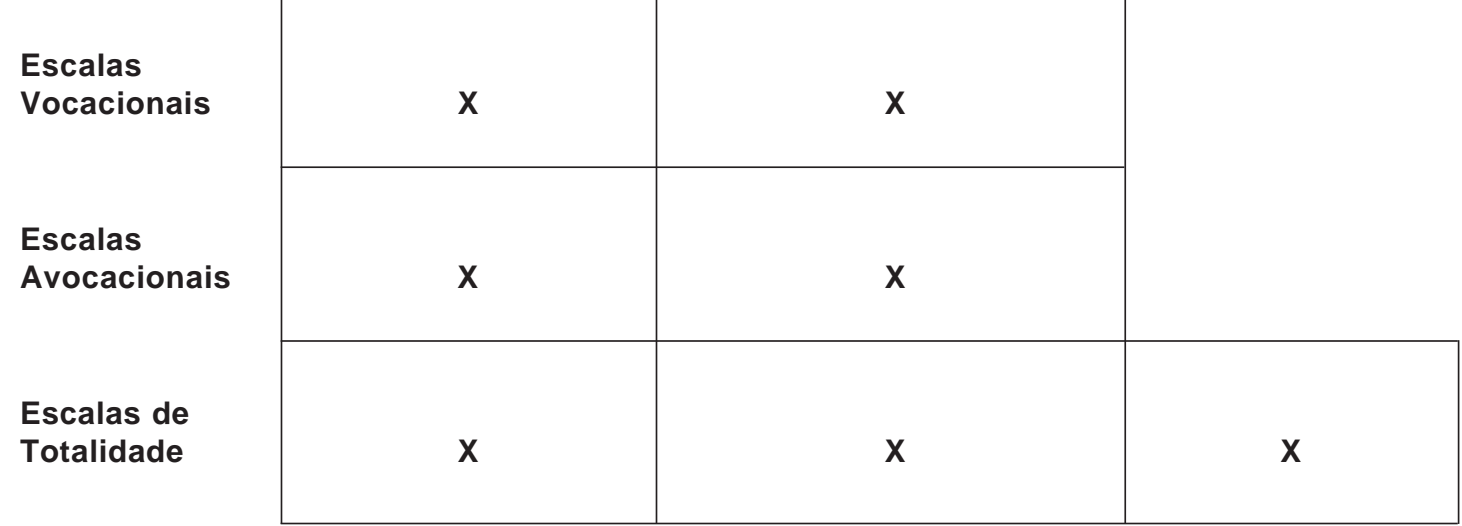

Legenda: Esquema Teórico utilizado pelas Escalas de Criatividade ao Longo da Vida (ECLV) ${ }^{10}$

1) Pico de Criatividade. O objetivo aqui é encontrar a manifestação máxima de originalidade em uma "realização principal" (por exemplo, uma casa construída, uma campanha de publicidade), mais do que momentos muito breves de criatividade (por exemplo, uma boa piada, uma sugestão singular). Isto nos permite olhar para a completa expressão de um potencial criativo subjacente a uma realização na vida real e, desta forma, nos auxilia a descontar eventuais limitações na vida de uma pessoa (como, por exemplo, falta de recursos - tão comum em nosso país -, falta de oportunidades, períodos difíceis na vida, entre outros).

1.a) Pico de Criatividade Vocacional. É o nível máximo de inovação manifestado em uma importante realização durante o período de trabalho de uma pessoa. para os fatores genéticos.

2) Extensão da Criatividade. Este índice mede o quão pervasiva é a atividade criativa na vida de uma pessoa. As medidas de extensão medem "o quanto disso tem ocorrido". As medidas de extensão são feitas para refletir a motivação e a oportunidade para a criatividade mais do que a capacidade subjacente. Elas podem, portanto, potencialmente, apresentar alguma independência das medidas de pico criativo.

2.a) Extensão da Criatividade Vocacional. Refere-se à extensão do envolvimento em um empreendimento inovador no trabalho ao longo da vida adulta.

2.b) Extensão da Criatividade Não Vocacional: Refere-se à extensão do envolvimento em um empreendimento inovador em atividades de lazer ao longo da vida adulta. Esta medida é 
potencialmente um indicador melhor da motivação de um sujeito para a atividade criativa do que a extensão do envolvimento vocacional, porque tipicamente há menores restrições ambientais nas atividades de lazer do que nas atividades no local de trabalho.

2.c) Extensão da Criatividade - Vocacional e Não Vocacional. É a extensão de envolvimento em inovações demonstrado durante a vida adulta da pessoa em qualquer empreendimento, seja vocacional ou não vocacional. Este item permite se considerar a motivação geral de alguém para a originalidade e pode dar o melhor parâmetro para os fatores ambientais.

3) Criatividade Total: É a integração de todas as informações, tanto no nível máximo de criatividade (pico de criatividade), quanto na extensão do envolvimento criativo ao longo da vida adulta. Esta medida é um índice da realização das capacidades criativas de cada sujeito.

Cada uma destas medidas está baseada na atividade realizada ao longo da vida. A idade adulta é aqui definida tendo seu início quando um sujeito se torna auto-sustentável, se casa ou atinge 18 anos - o que ocorrer primeiro. Estas escalas usam seis pontos de aferição da criatividade: 1 - insignificante, 2 - menor, 3 algum, 4 - moderada, 5 - alta e 6 - criatividade excepcional. Os dados de confiabilidade e validade das ECLV foram baseados em três grandes amostras independentes, como descrito por Richards, Kinney e Benet ${ }^{10}$. Uma das amostras foi retirada de um estudo dinamarquês sobre Transtornos de Humor com um n de 174 sujeitos. Outros estudos de validação foram feitos a partir de grandes amostras $(n=173$ e 209) de controles normais. Estes sujeitos foram escoIhidos em toda a Dinamarca e representam uma grande variedade de fatores demográficos. A confiabilidade entre avaliadores variou de boa a excelente. Foi calculada para 10 sujeitos randomicamente selecionados de cada amostra. Para o grupo portador de Transtornos de Humor, as confiabilidades médias foram respectivamente: 0,76 para criatividade vocacional, 0,86 para criatividade não vocacional e 0,86 para a criatividade total. Para os controles normais, as confiabilidades foram: 0,87 para as medidas vocacionais, 0,91 para as medidas não vocacionais e 0,88 para a criatividade total. Há evidências bastante positivas tanto para a validade de conteúdo e de construto destas escalas, quanto para a validade discriminante.

\section{UTILIZANDO AS ECLV}

A entrevista para posterior preenchimento das ECLV deve ser feita no sentido de se colher extensamente dados tão completos quanto possível de história de vida. Estes dados devem incluir informações acerca da história de atividades ao longo da vida adulta, tanto no trabaIho, quanto no lazer. Idealmente, devem ser colhidas descrições detalhadas sobre o trabaIho e caracterizações cuidadosas de atividades não vocacionais. O que é mais importante não é o trabalho ou o título do trabalho (ou o hobby ou seu título), mas como a pessoa efetivamente o realiza. A entrevista, portanto, é do tipo aberta e exploratória (se possível, filmadas e gravadas para posterior transcrição). O ideal seria observar as seguintes recomendações: a) utilizar um entrevistador experiente e sensível, de quem se esperaria uma capacidade de obter informações pessoais de forma bastante aberta e não diretiva, b) o entrevistador deve estar cego para as variáveis de interesse no estudo, assim como para o status do entrevistado, c) obter a história de vida do entrevistado sem ênfase óbvia na criatividade como foco primário da entrevista, d) escrever tão pronto quanto possível os resultados detalhados da entrevista - se esta não for filmada.

\section{DESENVOLVIMENTO DA VERSÃO DAS ECLV PARA O PORTUGUÊS}

O processo de tradução do Instrumento para a Língua Portuguesa teve as seguintes etapas:

a) Permissão pelos autores. A primeira autora das referidas Escalas (Ruth Richards) foi contatada via e-mail e solicitou-se a sua permissão para realizar a tradução das mesmas, obtendo-se a sua autorização.

b) Tradução. A tradução foi inicialmente realizada por alguns dos autores do presente artigo (FS, BM, GM, MB). Esta primeira versão para o português foi revisada por um painel composto por estes autores mais um outro colega (MF). Após discussões iniciais, foram realizados ajustes e uma primeira versão foi considerada aceitável. O próximo passo foi o envio da mesma para uma pessoa bilíngüe com vasta experiência em traduzir e retrotraduzir escalas em Psiquiatria. A tradutora realizou, então, a retrotraducão da versão para a Língua Inglesa.

c) Painel Bilíngüe. Esta retrotraducão para o inglês foi enviada para dois dos autores das Escalas (Ruth Richards em San Francisco, Ca- 
lifórnia e Dennis Kinney em Boston, Massachussets). Ambos autores realizaram comentários detalhados sobre a versão retrotraduzida.

d) Discussão das dúvidas. Seguiram-se a estes comentários algumas trocas de e-mails entre o grupo brasileiro e os autores americanos para dirimir dúvidas, assim como para adaptar as sugestões à versão em português.

e) Re-envio para os autores. Após as modificações realizadas na versão em português, foi re-enviado o Instrumento para os autores americanos. Finalmente, após um consenso geral de ambos os grupos, foi considerada terminada a versão para a Língua Portuguesa das Escalas de Criatividade ao Longo da Vida de Richards, Kinney e Benet ${ }^{10}$.

\section{CONCLUSÕES}

Sendo a capacidade criativa algo que pode ter importante impacto sobre a qualidade de vida tanto das pessoas em particular, quanto das sociedades em geral, pesquisas sobre este tema merecem ser desenvolvidas. Para tanto, são bem-vindos instrumentos válidos e confiáveis, que possam objetivamente tentar medir algo tão complexo e subjetivo como a criatividade. Neste sentido, as Escalas de Criatividade ao Longo da Vida (ECLV) poderão ser úteis para futuros estudos sobre a criatividade diária envolvendo uma ampla variedade de tópicos e delineamentos de pesquisas. Estas pesquisas poderão ajudar a responder, por exemplo, como nós, enquanto indivíduos, poderemos melhor promover a criatividade em amplas áreas de atividades, incluindo tecnologia, ciência, negócios, cultura, política e ética. Isto poderá nos capacitar a resolvermos de forma mais adequada os sérios problemas econômicos, ambientais e desafios políticos pelos quais passa a humanidade. As ECLV poderão também facilitar bastante a pesquisa de como os pais, os professores, os empregadores e outros poderiam melhor educar, cuidar e estimular a criatividade diária de pessoas não eminentes. Uma das principais qualidades das ECLV é de que elas avaliam a criatividade em situações da vida real, podem ser aplicadas a qualquer pessoa adulta e reconhecem como potencialmente criativas múltiplas áreas de atividades, e não apenas áreas especiais (como as artes e as ciências, por exemplo).

Finalmente, a avaliação de aspectos positivos da personalidade - como a capacidade criativa - parece estar recebendo cada vez maior interesse de pesquisas em Psiquiatria, sentido, a disponibilidade de um Instrumento em Português para pesquisadores brasileiros que meça a criatividade pode oferecer boas perspectivas para futuras pesquisas sobre este tema em nosso país. Estando agora já traduzidas para o português, as ECLV aguardam estudos de sua validação em nosso meio com possíveis diferenças culturais que possam aparecer em tais estudos.

\section{REFERÊNCIAS BIBLIOGRÁFICAS}

1. Barron F, Harrington D. Creativity, intelligence and personality. Ann Rev of Psychology 1981; 32: 439-476.

2. Hocevar D, Bachelor P. A taxonomy and critique of measurements used in the study of creativity. In: Glover JA, Ronning RR, Reynolds CR, editors. Handbook of creativity. New York: Plenum Press; 1989.

3. Torrance EP. Torrance Tests of creativity thinking: norms - technical manual. Princeton: Personnel Press/ Ginn; 1974.

4. Torrance EP, Ball OE. Torrance Tests of creative thinking streamlined manual (revised). Figural A and B. BenseviIle: Scholastic Testing Service; 1984.

5. Torrance EP. Growing up creatively gifted: a 22 year longitudinal study. Creative Child and Adult Quart 1980; 5: 148-158.

6. Akiskal HS, Akiskal K. Reassessing the prevalence of bipolar disorders: clinical significance and artistic creativity. Psychiatry and Psychobiology 1988; 3: 29-36.

7. Andreasen NC. Creativity and mental illness: prevalence raters in writers and their first-degree relatives. Am J Psychiatry 1987; 144: 1288-1292.

8. Jamison KR. Mood disorders and patterns of creativity in British writers and artists. Psychiatry 1989; 52: 125-134.

9. Richards R. Relationships between creativity and psychopathology: an evaluation and interpretation of the evidence. Genetic Psychol Monographs 1981; 103: 261324.

10. Richards RL, Kinney DK, Benet M. Assessing everyday creativity: characteristics of the Lifetime Creativity Scales and validation with three large samples. J Personality and Social Psychol 1988; 54: 476-485.

11. Maslow AH. Toward a psychology of being. New York: Van Nostrand; 1968.

12. Rogers CR. On becoming a person. Boston: HoughtonMifflin; 1961.

13. Dobzhansky T. Mankind evolving. New Haven: Yale University Press; 1962.

\section{RESUMO}

A criatividade não está confinada apenas a momentos de excelência nas Artes ou nas Ciências. É algo que ocorre também no dia-a-dia de pessoas não-eminentes e em uma ampla variedade de outras áreas. Com o intuito de acessar tanto a qualidade quanto a quantidade de realizações criativas na vida adulta de um indivíduo, é que foram desenvolvidas as Escalas de Criatividade ao Longo da Vida (ECLV) de Richards, Kinney e Benet. O foco destas escalas 
está nas atividades da vida real de uma determinada pessoa, tanto no trabalho quanto no lazer. As variáveis centrais da criatividade utilizadas por estas escalas são: (a) pico de criatividade, (b) extensão do envolvimento criativo e (c) uma estimativa da criatividade total. O presente artigo apresenta estas escalas descrevendo o instrumento propriamente dito, assim como o desenvolvimento de sua versão para a Língua Portuguesa. Entendem os autores do presente artigo que a disponibilidade de um Instrumento em Português para pesquisadores brasileiros na área da criatividade pode oferecer boas perspectivas para futuras pesquisas sobre este tema em nosso país.

Descritores: Criatividade, psiquiatria, tradução (processo).

\section{ABSTRACT}

The importance of creativity is not limited only to moments of excellence, whether it be in Arts or Sciences. It is something that also takes place in the daily life of non-eminent people. The Lifetime Creativity Scales (LCS) by Richards, Kinney and Benet were developed for the purpose of measuring different dimensions, both as to vocational and nonvocational creativity. The purpose of this paper is to describe the characteristics of the LCS and to present the methodology used for the development of the Portuguese-language version of these Scales. The availability of a Portuguese-language Instrument for Brazilian researchers to measure creativity may offer good prospects for future research on this topic in our country.

Keywords: Creativeness, psychiatry, translating.

Title: Development of the Portuguese-language version of the Lifetime Creativity Scales (LCS)

\section{RESUMEN}

La creatividad no está confinada apenas a momentos de excelencia en las Artes o en las Ciencias. Es algo que ocurre también en el día a día de las personas no-eminentes y en una amplia variedad de otras áreas. Con el propósito de acceder tanto a la cualidad como a la cantidad de realizaciones creativas en la vida adulta de un individuo, es que fueron desarrolladas las Escalas de Creatividad a lo Largo de la Vida (ECLV) de Richards, Kinney y Benet. El foco de estas escalas está en las actividades de la vida real de una determinada persona, tanto en el trabajo cuanto en el ocio. Las variables centrales de la creatividad utilizadas por estas escalas son: a) pico de creatividad, b) extensión del envolvimiento creativo y c) una estimativa de la creatividad total. El presente artículo presenta estas escalas describiendo el instrumento propiamente dicho, así como el desenvolvimiento de su versión para la lengua portuguesa. Los autores del presente artículo entienden que la disponibilidad de un instrumento en portugués para investigadores brasileños en el área de creatividad puede ofrecer buenas perspectivas para futuras pesquisas sobre este tema en nuestro país.

Palabras-clave: Creatividad, psiquiatría, traducción (proceso).

Título: Desarrollo de la versión para la lengua portuguesa de la Escala de Creatividad a lo largo de la Vida (LCS)

Endereço para correspondência: Flávio Shansis

Av. Taquara, 586/606 - Petrópolis 90.460-210 - Porto Alegre - RS E-mail: shansis.ez@terra.com.br

Copyright (C) Revista de Psiquiatria do Rio Grande do Sul - SPRS 


\section{ANEXO 1}

\section{ESCALAS DE CRIATIVIDADE AO LONGO DA VIDA (ECLV)}

Ruth Richards, Dennis Kinney e Maria Benet.

Versão para o Português de Shansis et al, 2003.

\section{CRITÉRIOS E EXEMPLOS: VARIÁVEIS DE CRIATIVIDADE}

\section{1 (A). PICO DE CRIATIVIDADE - VOCACIONAL}

Diretrizes: • pico de inovação em um importante empreendimento.

- baseado na atividade vocacional ao longo da vida adulta.

- pontuação substituta [\#1(B)] se a informação for limitada.

Escala: $\frac{0}{\text { nenhuma }} / \frac{1}{\text { menor }} / \frac{2}{\text { alguma }} / \frac{3}{\text { moderada }} \frac{4}{\text { alta }} / \frac{5}{\text { excepcional }}$

[0] - Criatividade Não Significativa (atividades pré-determinadas ou rotineiras com aspectos inovadores negligenciáveis). Exemplos: atividade rotineira como carregador de tijolos ou lavador de janelas; tarefas variadas operando um painel de controle, todas envolvendo procedimentos préestabelecidos.

[1] - Grau Menor de Criatividade (pequenos afastamentos usuais da rotina ou de tarefas prédeterminadas). Exemplos: instrutor de informática que faz poucas intervenções; pintura de desenhos padronizados em souveniers; vendedor de banca de jornais que trabalha e interage de forma rotineira.

[2] - Alguma Criatividade (inovação maior, mas não incomum na população - isso pode envolver alguma variação nos produtos ou práticas comuns ). Exemplos: pintar desenhos padronizados ou decorar produtos de padaria com algumas modificações individuais; conferências baseadas em um material padronizado; trabalho de carpintaria que requer decisões "na hora" sobre o uso de materiais e coordenação dos elementos construídos; gerenciamento envolvendo habilidades organizacionais e interpessoais de uma natureza relativamente comum.

[3] - Criatividade Moderada (presença de elementos inovadores centrais que se destacam na população, embora não marcadamente - isso pode envolver importantes modificações de práticas ou resultados comuns). Exemplos: instrução usando programas de aula variáveis e técnicas interativas; desenhista de retratos que captura diferentes tipos de pessoas; agricultura envolvendo rotação de culturas inusuais e outros ajustamentos flexíveis ao meio ambiente; gerenciamento de uma variedade de pessoas, departamentos ou situações que requerem iniciativa e novas abordagens para resolução de problemas; planejamento culinário caracterizado por combinações inusuais de ingredientes e pratos.

[4] - Alta Criatividade (presença de elementos marcadamente distintos e inovadores que caracterizam a atividade como muito diferente das outras na população). Exemplos: desenvolvimento de um currículo altamente inovador; trabalho artístico caracterizado por temas, interpretações ou características estilísticas formais marcadamente inusuais; importantes façanhas empresariais em áreas novas e arriscadas; trabalho diagnóstico astuto em doenças confusas ou sintomas complexos; importantes contribuições ao desenho de obras modernas da engenharia.

[5] - Criatividade Excepcional (iniciativas radicais a partir do lugar comum - e estas podem exigir reorganização conceitual ou reavaliação experimental para serem assimiladas). Exemplos: 
desenvolvimento de novos conceitos e estruturas educacionais; avanços tecnológicos (por ex., "olhos para cegos" - transdução de sinais visuais para sensores cutâneos); modos de expressão artística (por ex., nova escala tonal); ou estruturas organizacionais (por ex., equipes de trabalho vs. linha de montagem na construção de automóveis).

\section{1 (B). PICO DE CRIATIVIDADE - VOCACIONAL (PONTUAÇÃO SUBSTITUTA)}

Diretrizes: • pico de criatividade pelo tipo de ocupação.

- pontuação substituta para \#1(A) se a descrição profissional for limitada.

- "melhor estimativa" baseada no desempenho médio de trabalhos específicos em uma população dinamarquesa.

- ver Apêndice para pontuações.

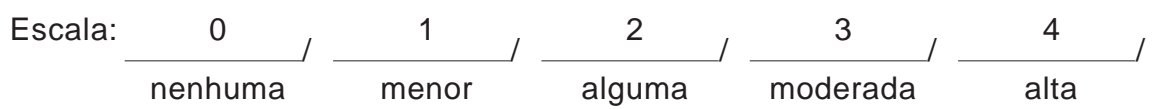

[0] - Criatividade Não Significativa (atividades rotineiras ou pré-determinadas com aspectos inovadores negligenciáveis). Exemplos: trabalhador de fábrica sem habilidade, lavadeira, caixa.

[1] - Grau Menor de Criatividade (pequenos afastamentos usuais da rotina ou das atividades pré-determinadas). Exemplos: gesseiro, técnico em um laboratório clínico, despachante.

[2] - Alguma Criatividade (inovação maior, mas não incomum na população - pode envolver alguma variação nos produtos ou práticas ou comuns). Exemplos: pescador, nutricionista, vendedor em uma loja de roupas.

[3] - Criatividade Moderada (presença de elementos inovadores centrais que se destacam na população, embora não marcadamente; pode envolver importantes modificações de práticas ou produtos comuns). Exemplos: detetive, vitrinista, repórter.

[4] - Alta Criatividade (presença de elementos marcadamente distintos e inovadores que caracterizam a atividade como muito diferente das outras na população). Exemplos: "chef' (culinário), professor, romancista, importante empresário.

\section{EXTENSÃO DO ENVOLVIMENTO - VOCACIONAL}

Diretrizes: - Grau de envolvimento criativo longo da vida.

- Qualquer atividade pode ser considerada como de "menor" ou maior criatividade.

- Apenas os componentes criativos das atividades contribuem para a determinação da extensão.

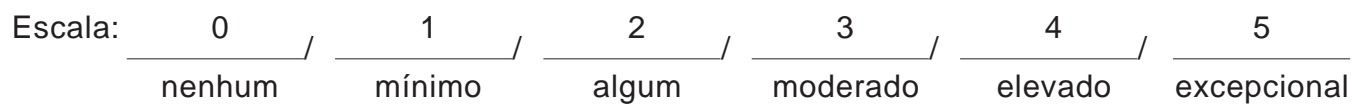

[0] - Sem Envolvimento Significativo ( atividades ao longo da vida com padrão rotineiro ou altamente pré-determinado). Exemplos: carreira como organizador de arquivos e controlador de cartões magnéticos (p.ex., passar cartão magnético na entrada do cinema); trabalho sem qualificação em vários empregos na indústria.

[1] - Menor Grau de Envolvimento ( padrão pré-determinado ou rotineiro rompido por breves e raros exemplos de atividade inovadora). Exemplos: trabalho como motorista de uma companhia rompido por períodos muito breves de trabalho autônomo; trabalho de taquigrafia envolvendo algumas raras, mas importantes, funções de edição. 
[2] - Algum Envolvimento (maior extensão de atividade inovadora que os itens acima, mas não incomum na população - e outra atividade não-inovadora tende a predominar). Exemplos: datilógrafo de longa data que finalmente consegue um emprego de secretário, permitindo alguma iniciativa em gerenciamento de escritório; padeiro cuja rotina de trabalho é rompida por ocasiões em que ele desenvolve novos produtos; assistente de loja que periodicamente planeja novas exposições e organização da vitrine; recepcionista que uma vez ensinou costura; um idoso trabalhador rural que já foi campeão de boxe.

[3] - Envolvimento Moderado (atividade inovadora notável em um padrão que tende a mesclar esta com outras formas de empreendimento). Exemplos: trabalhador de fábrica que exerceu atividades sindicais por muitos anos; publicitário cujo trabalho é reconhecido como altamente criativo mas dedicou apenas parte do seu tempo aos aspectos mais inovadores; assistente administrativo que apresentou muita iniciativa na reorganização do escritório ao longo dos anos; cozinheiro com carreira em vários hotéis que após adquire e gerencia seu próprio restaurante em um barco de passeio.

[4] - Elevado envolvimento ( ênfase marcadamente característica na inovação; um tema dominante na vida e um compromisso primário). Exemplos: ilustrador de livros, artista independente; professor de arte que teve pouco sucesso, mas investiu muita energia em atividades inovadoras; publicitário especialista em novas campanhas; empresário que iniciou uma variedade de novos negócios; decorador de interiores por muitos anos, que uma vez foi vendedor numa loja de departamentos; jornalista que se tornou subeditor chefe num jornal, adicionando maiores responsabilidades gerenciais a sua contínua atividade literária; professora de artesanato por longo tempo; líder e organizador político por 50 anos.

[5] - Envolvimento Excepcional (preocupação intensa, dominante e talvez compulsiva com atividades inovadoras, excluindo virtualmente outras atividades). Exemplos: restaurador e negociante em antiquário que tende a trabalhar por longo tempo em restauração, desenhando nas horas livres quando possível; cientista que passou muito tempo no laboratório perdendo refeições e ficando acordado até tarde por muitos anos.

\section{PICO DE CRIATIVIDADE - NÃO VOCACIONAL}

Diretrizes: • Pico de inovação em um importante empreendimento.

- Baseado em uma atividade adulta não vocacional.

- Conquistas em níveis mais altos podem atingir reconhecimento social, apesar disso não ser requerido.

Escala: $\frac{0}{\text { nenhum }} / \frac{1}{\text { menor }} / \frac{2}{\text { algum }} / \frac{3}{\text { moderado }} / \frac{4}{\text { elevado }} / \frac{5}{\text { excepcional }}$

[0] - Criatividade Não Significativa (atividades rotineiras ou pré-determinadas que negligenciam aspectos inovadores). Exemplos: freqüenta eventos esportivos, lê revistas, assiste televisão, ou outra atividade passiva; pinta seguindo modelos; coleciona selos em livretos que especificam as seleções a serem procuradas.

[1] - Menor Grau de Criatividade (pequenos afastamentos usuais da rotina ou de tarefas prédeterminadas). Exemplos: mecânico de carros amador que gosta de fazer reparos eventuais no motor do carro; fazer tricô; costura; monta modelos pré-fabricados (p.ex., aeromodelos ) sem características especiais.

[2] - Alguma Criatividade (inovação maior, mas não incomum na população-pode envolver alguma variação em práticas ou produtos comuns). Exemplos: planta variados jardins a cada ano; constrói móveis ou faz tapeçaria com algumas modificações individuais das instruções; faz reparos variados na casa; canta no coral da comunidade. 
[3] - Criatividade Moderada (presença de elementos inovadores centrais que se destacam na população, embora não marcadamente; isso pode envolver modificações maiores de práticas ou produtos comuns). Exemplos: pinta temas comuns fazendo adaptações com estilo próprio; constrói modelos ou desenvolve receitas com estilo amplamente pessoal; cria um sistema incomum de irrigação para o jardim; adapta e cria equipamento de pescaria para circunstâncias especiais.

[4] - Alta Criatividade (presença de elementos marcadamente distintos e inovadores que caracterizam a atividade como muito diferente das outras na população). Exemplos: constrói uma parte adicional à casa com seu próprio desenho; descobre e ajuda a escavar um campo arqueológico na região; desenvolve uma obra artística diferenciada (p.ex., uma série de esculturas), que é exposta em outro país; atua inovadoramente em papéis principais em um grupo de teatro local; desenvolve astutamente operações de espionagem como parte do movimento de resistência da Segunda Guerra Mundial.

[5] - Criatividade Excepcional (iniciativas radicais a partir do lugar comum - e estas podem exigir reorganização conceitual ou reavaliação experimental para serem assimiladas). Exemplos: esculpe estruturas que são transformadas visual e cineticamente com a variação climática e são repetidamente fotografadas; constrói um complexo e amplamente noticiado aparato para ajudar seu filho deficiente físico a se movimentar e aprender a manipular objetos.

\section{EXTENSÃO DO ENVOLVIMENTO CRIATIVO - NÃO VOCACIONAL}

Diretrizes: • grau de envolvimento criativo ao longo da vida.

- nesta avaliação são consideradas atividades que demonstram "menor" ou maior nível de criatividade.

- nesta avaliação são considerados apenas os aspectos criativos das atividades.

Escala: $\frac{0}{\text { ausente }} / \frac{1}{\text { menor }} / \frac{2}{\text { algum }} / \frac{3}{\text { moderado }} / \frac{4}{\text { alto }} / \frac{5}{\text { excepcional }}$

[0] - Envolvimento não significativo (atividades ao longo da vida seguem um padrão passivo, rotineiro, altamente pré-determinado). Exemplos: pessoa que dedica o tempo à leitura, a ver televisão e a assistir eventos esportivos.

[1] - Grau menor de envolvimento (padrão determinado ou rotineiro, alterado por raros e fugazes instantes de atividades inovadoras). Exemplos: pessoa que assume papel de figurante de uma produção teatral a pedido de uma amigo; "tira algumas fotos" em viagens; faz um pouco de tricô.

[2] - Algum envolvimento (atividade inovadora de maior extensão do que as acima citadas mas não incomum na população, sendo que outras atividades não criativas tendem a predominar)

Exemplos: pessoa que ocasionalmente treina um time local, faz roupas ou constrói casas de passarinho; trabalha intensamente em reparos domésticos após adquirir uma casa, mas, afora isso, tem sido relativamente inativa.

[3] - Envolvimento moderado (atividade inovadora notável em um padrão que tende a mesclar-se com outras formas de empreendimento). Exemplos : pessoa que regularmente tem assistido e participado de aulas de artesanato e realizado trabalhos manuais em casa durante muitos anos; pessoa que passou alguns anos em uma atividade de vida não convencional, trabalhando regular e intensamente em um romance; dedicado pescador que passou muito tempo durante sua vida desenvolvendo o seu próprio equipamento; entusiasta de dança folclórica que geralmente dança com seu companheiro(a) e regularmente compete em torneios locais; pessoa que geralmente tricota em casa enquanto recebe visitas, e durante outras atividades. 
[4] - Alto Envolvimento (ênfase distintamente marcada em inovações; um tema dominante na vida e um compromisso primário) Exemplos: uma pessoa que durante sua vida apresenta envolvimentos variados em pintura, construção, reparos domésticos e jardinagem, durante grande parte de seu tempo livre; pessoa que gasta períodos intermitentes em um esforço intenso para achar e restaurar antiguidades para a sua casa; pessoa inventiva que tem trabalhado regularmente em barcos, bicicletas e rádios, durante os anos; artista amador que realizou muitos desenhos durante sua vida e que agora desenha e faz colagens com seu filho, bem como gasta seu tempo com decoração interior.

[5] - Envolvimento excepcional (preocupação intensa, dominante e talvez compulsiva com atividades inovadoras, excluindo virtualmente outras atividades). Exemplos: escritor constantemente ativo que sempre anda com papel e caneta e os deixa ao lado da cama para aproveitar inspirações momentâneas; pessoa que restringe suas horas de trabalho, pode chegar a pedir uma licença de dois anos e pode manter um "dia de 20 horas" para completar experimentos em botânica.

\section{NÍVEL MÁXIMO DE CRIATIVIDADE (AVALIAÇÃO GLOBAL)}

Diretrizes: - nível máximo de criatividade demonstrado durante a vida adulta em qualquer empreendimento.

- esta escala representa o máximo de graduação criativa em aspectos vocacionais e não vocacionais.

Escala: $\frac{0}{\text { ausente }} / \frac{1}{\text { menor }} / \frac{2}{\text { algum }} / \frac{3}{\text { moderado }} / \frac{4}{\text { alto }} / \frac{5}{\text { excepcional }}$

\section{EXTENSÃO DO ENVOLVIMENTO CRIATIVO}

Diretrizes: - extensão do envolvimento em todas as formas de empreendimento criativo ao longo da vida adulta.

- as avaliações são feitas de maneira diferente do que na \#2 e \#4.

- as atividades vocacional e não vocacional podem contribuir para essa avaliação em proporções variáveis, dependendo de como os sujeitos distribuíram o seu tempo e suas energias inovadoras.

Escala: $\frac{0}{\text { nenhum }} / \frac{1}{\text { menor }} / \frac{2}{\text { algum }} / \frac{3}{\text { moderado }} / \frac{4}{\text { alto }} / \frac{5}{\text { excepcional }}$

[0] - Sem Envolvimento Significativo (padrão de atividade ao longo da vida altamente prédeterminado, rotineiro ou passivo). Exemplos: taquígrafo e balconista que realizaram tarefas rotineiras e cujo tempo excedente foi dedicado à leitura, a assistir televisão e a outras atividades passivas.

[1]-Menor Grau de Envolvimento (padrão pré-determinado interrompido por momentos breves e raros de atividade inovadora). Exemplos: trabalhar como assistente de uma loja de laticínios seguido por um período prolongado como cozinheiro com muita atividade de serão e poucas ocasiões para lazer. O indivíduo fez uma mudança inovadora enquanto trabalhava na loja de laticínios, mas, de outra forma, realiza funções que permitem apenas pequenos afastamentos da rotina.

[2] - Algum Envolvimento (extensão maior de atividade inovadora que os acima, mas não incomum para a população - outra atividade não criativa tende a predominar). Exemplos: pedreiro que tem feito trabalho rotineiro por muitos anos e que, no período de lazer, tende a relaxar, se socializar e a ir a eventos esportivos. Entretanto, ele periodicamente se envolve em reparos 
domésticos e modificações que requerem soluções inovadoras e, às vezes, repara para amigos também.

[3] - Envolvimento Moderado (quantidade notável de atividade inovadora num padrão que tende a mesclar isso com outras formas de empreendimento). Exemplo: vendedor de roupas que mais tarde se torna gerente regional de vendas, um trabalho que fornece continuamente problemas e desafios, e cuja atividade de lazer incluiu fazer ornamentos adaptados de designs antigos, juntamente com quantidades variadas de tricô, costura e jardinagem.

[4] - Alto Envolvimento (ênfase distintamente marcada na inovação - um tema dominante na vida e um compromisso primário). Exemplo: um negociante de equipamentos usados que utiliza seu local de trabalho e sua casa para a coleção de bugigangas, invenção de ferramentas e restauração de itens incomuns, que obtém uma segunda renda através do comércio e da venda de peças e que continua, por longo tempo, sendo membro ativo de um clube de pessoas envolvidas em um hobbie comum, como um de seus diretores.

[5] - Envolvimento Excepcional (preocupação intensa, dominante e talvez compulsiva com atividades inovadoras, excluindo virtualmente outras atividades). Exemplo: jornalista altamente ativo que pesquisa e escreve regularmente reportagens, está trabalhando em casa em um livro de uma série, que tocou piano por anos e o pratica diariamente e tem muito pouco tempo que não é distribuído entre essas várias atividades.

\section{CRIATIVIDADE TOTAL}

Diretrizes: • uma medida composta integrando dados sobre criatividade e extensão do envolvimento ao longo da vida.

- simplificadamente, essa "integração" considera a criatividade média X o percentual do ciclo vital devotado à atividade criativa.

- entretanto, nos níveis mais altos de criatividade, o envolvimento corrente é visto como potencialmente menos importante para o "retrato" total de realizações e pode ser considerado apenas secundariamente.

- determinações tem como intenção evocar o sentido subjetivo do avaliador com relação a cada indivíduo (assim como considerações mais mecânicas).

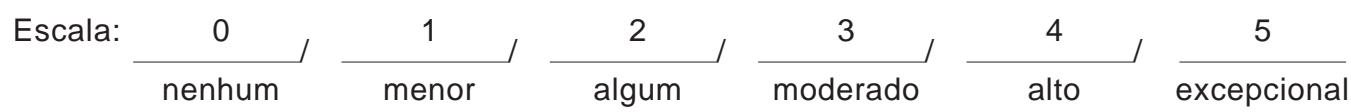

[0] - Sem Criatividade Significativa: um padrão de atividades rotineiras ou pré-determinadas ao longo da vida adulta.

[1] - Menor Grau de Criatividade: um padrão com poucos afastamentos das atividades prédeterminadas ou rotineiras; estes afastamentos vão raramente ser nos níveis mais altos de inovação.

[2] - Alguma Criatividade: um padrão com envolvimento periódico ou corrente leve-moderado em atividades inovadoras - menos comumente nos níveis mais altos de inovação.

[3] - Criatividade Moderada: um padrão intermediário de envolvimento periódico ou corrente em empreendimentos que podem variar amplamente no nível de inovação - aproximadamente na proporção inversa da extensão de envolvimento.

[4] - Alta Criatividade: um padrão que varia da atividade ocasional, mas intensa, num alto nível de inovação até o envolvimento consistentemente forte em atividades no grau intermediário de inovação. 
[5] - Criatividade Excepcional: um padrão que potencialmente inclui um nível excepcional de inovação, mesmo que em um nível relativamente baixo de envolvimento, e inclui alguns casos de inovação moderadamente alta se a extensão do envolvimento é impressionante. 